Original Research Paper

\title{
Design and Analysis of Bipolar Plate for 500w Pem Fuel Cell Stack
}

\author{
A. Kalaiyarasan, C. Srinivasan and S. Sundaram \\ Department of Mechanical Engineering, Muthayammal Engineering College, (Autonomous) Rasipuram, Tamilnadu, India
}

\author{
Article history \\ Received: 11-10-2017 \\ Revised: 02-11-2017 \\ Accepted: 13-01-2018 \\ Corresponding Author: \\ S. Sundaram \\ Department of Mechanical \\ Engineering, Muthayammal \\ Engineering College, \\ (Autonomous) Rasipuram, \\ Tamilnadu, India \\ Email: sundaram1160@gmail.com
}

\begin{abstract}
The PEM Fuel Cell (PEMFC) performance depends on the operating parameters like temperature, pressure, stoichiometric ratio of reactants, relative humidity, back pressure on anode and cathode flow channels, and the design parameters like rib width to channel width (L:C), channel depth, shape of the flow channel and number of pass on the flow channel. The voltage and power produced by single cell was not enough for practical applications, hence number of cells are connected in series or parallel to generate required current and voltage to form a fuel cell stack. The effective performance of fuel cell stack depends upon the satisfactory operation of individual cells. For effective thermal management, water management and distribution of reactants $\left(\mathrm{H}_{2}\right.$ and $\left.\mathrm{O}_{2}\right)$ is challengeable task in fuel cell stack. The design of bipolar plate is contributing more in PEM fuel cell stack to meet the above said critical parameters. In this paper numerical investigation of 500w PEM fuel cell stack with each cell of $100 \mathrm{~cm}^{2}$ active area with rib to channel width (L:C-2:2) of single pass, three pass and six pass parallel serpentine flow channel with square channel inlet and outlet were carried out. The three dimensional PEMFC stack with various passes $(1,3,6)$ for serpentine flow channel were modeled by pro-e, meshed by ICEM 14.0 software packages and simulated using CFD Fluent 14.0 under various operating pressure range from 1 bar to 2 bar and flow rate of hydrogen and oxygen as $500 \mathrm{ml} / \mathrm{min}$ and $250 \mathrm{ml} / \mathrm{min}$ respectively. The numerical modeling results on performance of PEMFC stack has been studied and compared and the better flow channel design was identified.
\end{abstract}

Keywords: Serpentine Flow Channel, Single Pass, Three Pass, Six Pass 3 Dimensional Flow Channel, Bipolar Plate, Operating Pressure and Velocity, CFD Analysis of PEMFC

\section{Introduction}

The Polymer Electrolyte Membrane (PEM) fuel cell are a promising candidate has zero-emission power source for transport and stationary cogeneration applications due to its very high efficiency, lowtemperature operation, high power density, fast startup, and system robustness. Bipolar plate is a vital component of PEM fuel cells, which supplies fuel and oxidant to reactive sites, removes reaction products, collects produced current and provides mechanical support for the cells in the stack. Bipolar plates constitute more than $60 \%$ of the weight and $30 \%$ of the total cost in a fuel cell stack. The proton exchange fuel cells are environment friendly power source and are suitable for powering both portable devices and mobile application due to their high energy density and lower operating temperature range viz, $30^{\circ} \mathrm{C}-70^{\circ} \mathrm{C}$ (Frano, 2005). The PEMFC consists of polymer solid electrolyte membrane (Nafion) placed between two electrodes namely anode and cathode. The electrochemical reaction produces by-product of water and heat, along with electricity generation. The various flow channel design was used to obtain high current and peak power density, proper temperature distribution and optimum water management. The influence of impact of flow channel path length on PEM fuel cell flow field design has been addressed by Shimpalee and Vanzee (2006; Sun et al., 2006).

For a given Membrane/Electrode Assembly (MEA), the power density of a fuel cell stack can be significantly increased by reducing the profile of the bipolar plates Water flooding will make the PEM fuel cell performance unpredictable and unreliable under the nominally identical operating conditions. So the critical 
issue for PEMFCs can be resolved through the appropriate design of flow channels for effective removal of water built on the flow field (bipolar) plates. In order to enhance its performance and reliability, it is necessary to learn more about the mechanism that causes the performance loss, such as, non-uniform concentration, current density distributions, high ionic resistance due to dry membrane, or high diffusive resistance due to the flooding on the cathode has been addressed by Nattawut Jaruwasupant and Yottana Khunatorna (Liu et al., 2006; Chen, 2010). Hydration of membrane in the PEMFC is to maintain the performance, if it is not maintained properly, flooding and dehydration would occur which will affect the fuel cell performance (Jang et al., 2006; Colosquia et al., 2011). So identifying the proper channel and flow field design is a very important task while designing the fuel cell which also affects the performance of fuel cell significantly (Das et al., 2010). Generally the trend is going to do the analysis of PEM fuel cell with various flow field designs and their influence using Computational Fluid Dynamics (CFD) (Birgersson and Vynnycky, 2006). But, the influence of reactant distribution for all cells with required pressure in PEMFC stack has been not addressed on the previous studies. So, this paper addresses the pressure distribution in PEM fuel cell stack for serpentine flow channel of 500w PEMFC stack with single pass, three pass and six pass flow channels and influence of their performance. The fuel cell major component assembly is shown in Fig. (1).

\section{Bipolar Plate}

As explained earlier, BPPs account for the bulking of the stack, hence it is desirable to produce the plates with the smallest possible dimensions. The current density of single channel and double channel flow field were gradually varied (Jeon et al., 2008). With the bipolar plate arrangement for current collection each of the Membrane Electrode Assembly (MEAs) is interspersed between two fluid impermeable, electrically conductive plates, commonly referred to as the anode and the cathode plates, respectively. When the reactant flow channels are formed on the anode and cathode plates, the plates are normally referred to as fluid flow-field plates. When the flow channels are formed on both side of the same plate, one side serves as the anode plate and other side as the cathode plate to the adjacent cell, the plate is called bipolar (separator) plate, as shown in Fig. (2).

The development of three dimensional (3-D) PEMFC stack model with 1 pass, 3 pass and 6 pass serpentine flow channel of $(2 \times 2)$ configurations have involved three major steps. The first step involved, generation of 3-D model of PEMFC stack developed by pro-e as shown in Fig. 3. The modeling was done by creating individual parts of the PEMFC stack such as two unipolar plates and four bipolar plates, a separator to separate each cell. These parts were assembled using suitable constrains to form the 3-D PEMFC stack. The assignments of zones for various parts were done by Workbench 14.0. The dimensions, naming of the components and zone type were shown in Table 1.

\section{Pemfc Stack}

To develop 500w stack, it is necessary that each cell of stack should have active area not less than $100 \mathrm{~cm}^{2}$. The operating voltage will be $0.6 \mathrm{~V}$ and average current density will be $0.4 \mathrm{~A} / \mathrm{cm}^{2}$. Each stack consists of 5 cells connected in series to obtain $100 \mathrm{w}$ power.

Table 1: Dimensions and zone type assigning of fuel cell

\begin{tabular}{llllll}
\hline S. No & Part name $(\mathrm{mm})$ & Width $(\mathrm{mm})$ & Length $(\mathrm{mm})$ & Thickness $(\mathrm{mm})$ & Zone Type \\
\hline 1 & Flow field with single psss & 98 & 100 & 2 & Fluid \\
2 & Flow field with three pss & 154 & 150 & 2 & Fluid \\
3 & Flow field with six pass & 166 & 150 & 2 & Fluid \\
\hline
\end{tabular}

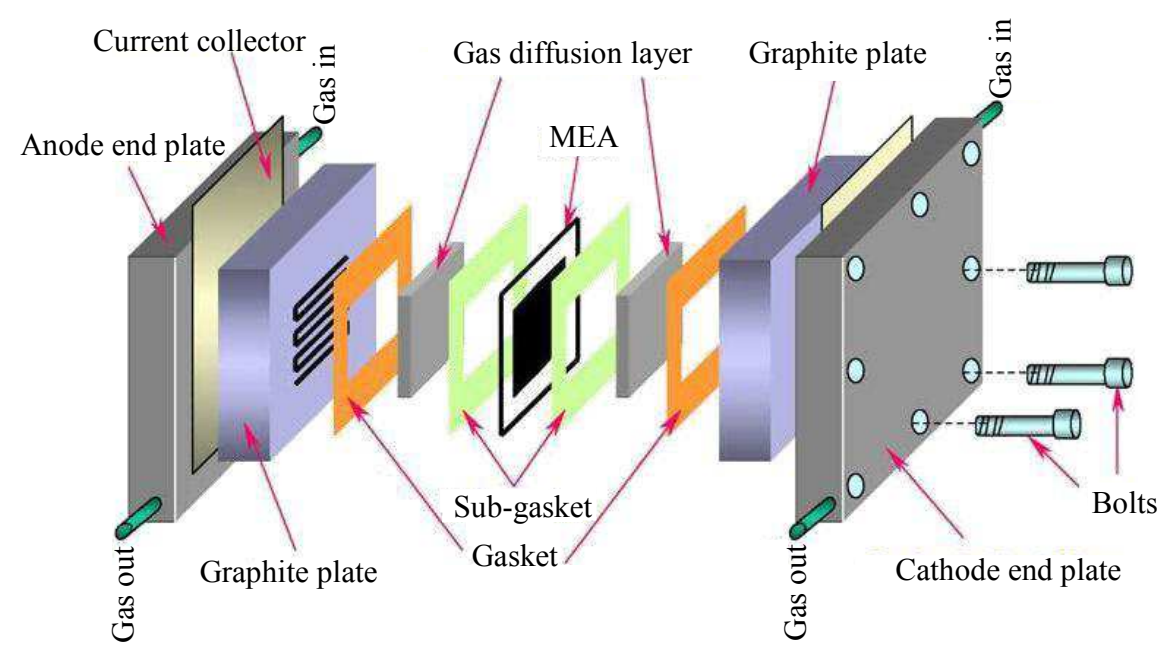

Fig. 1: Schematic of the typical PEM fuel cell used for testing of Membrane and Electrode Assembly (MEA) 


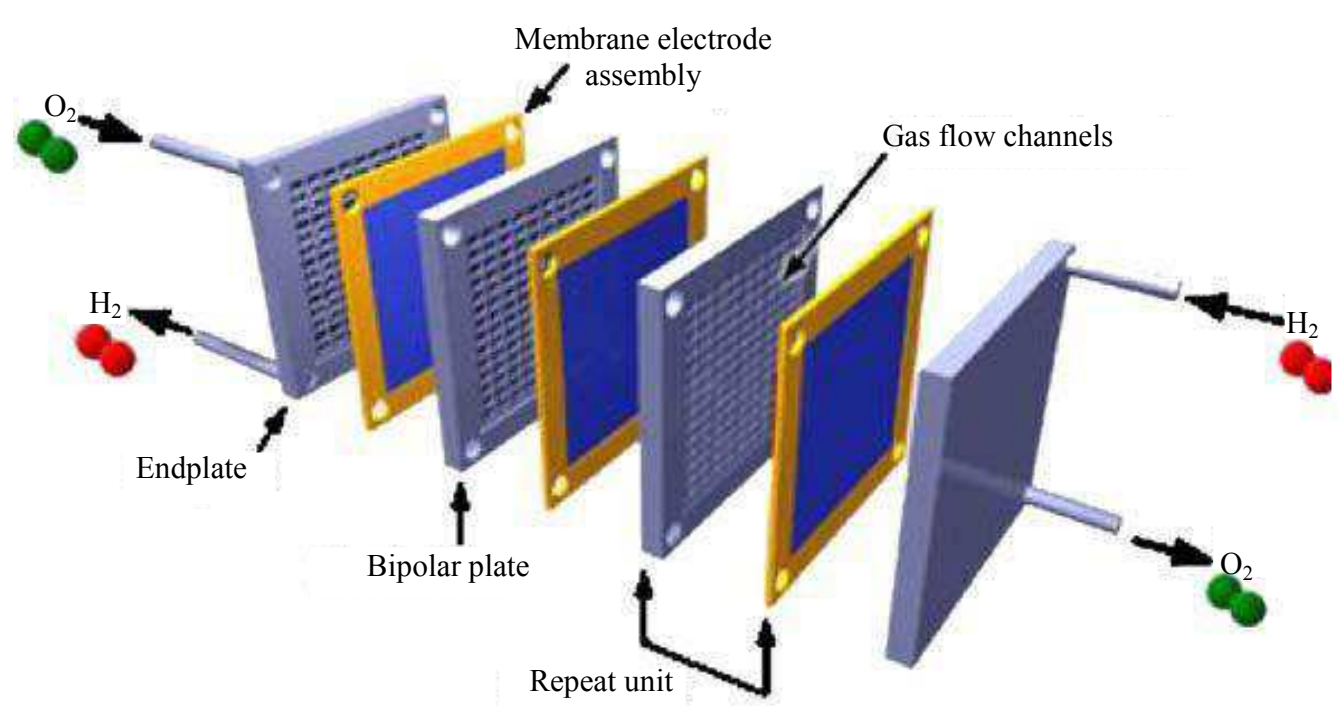

Fig. 2: Stack components of fuel cell

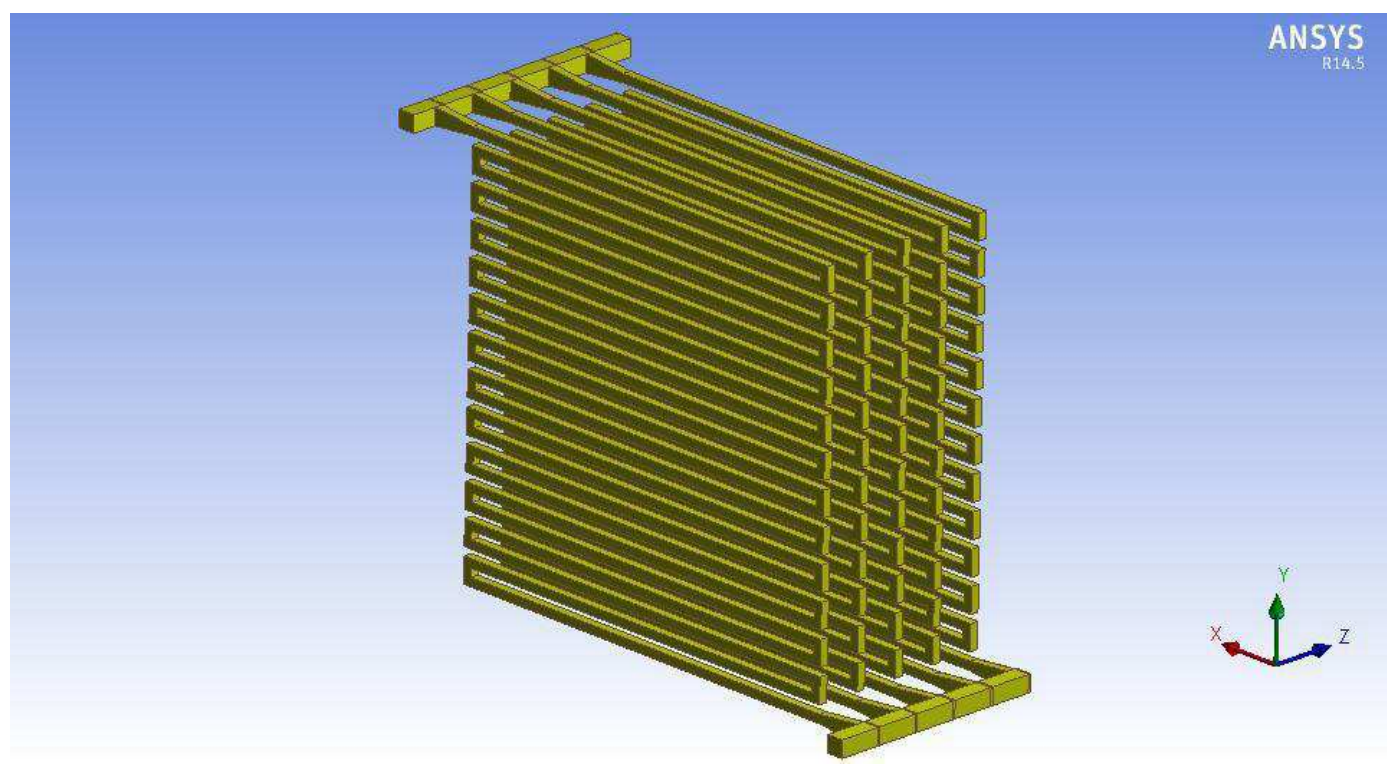

Fig. 3: $2 \times 2$ single channel parallel serpentine flow field

\section{Stack Modelling}

Three models having single channel (Fig. 3), three channels (Fig. 4) and six channels (Fig. 5) aligned in serpentine manner and consist of 2 unipolar plate and 4 bipolar plates are connected in series'. Both inlet and outlet $(4 \times 4 \mathrm{~mm})$ in all three configurations are connected in a common rail so that reactants are distributed to all the five cells of the stack. To avoid mixing of reactants at any zone, separator of $0.5 \mathrm{~mm}$ thickness is introduced between each plate.

It is necessary to study on flow distribution in each cell hence the created model is imported in fluent software and flow channel is separated from the model as shown in Fig. (3, 4 and 5) respectively.
Analysis

The analysis is carried out for the complete fuel cell stack model for the three different configurations using the ANSYS. This solves the fuel cell sub-model called flow sub model since the concentration is only on pressure distribution in each cell of the stack. The analysis part involves the following steps.

\section{Meshing}

The meshing method is used here is Cartesian grid which is help in forming of hexahedral mesh which gives accuracy result. The meshing of single pass flow field design is shown in Fig. (6). 


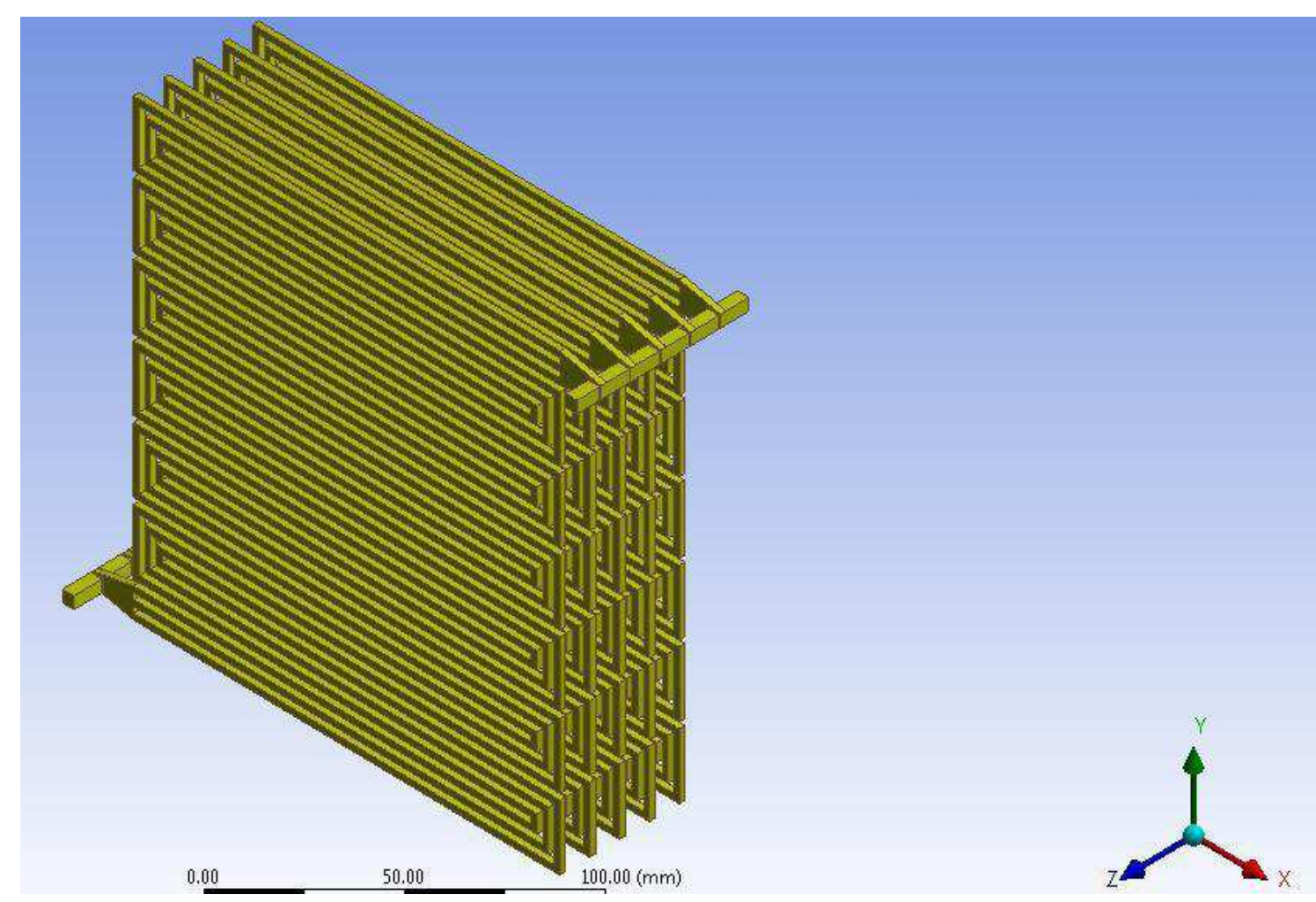

Fig. 4: $2 \times 2$ Three channel parallel serpentine flow field

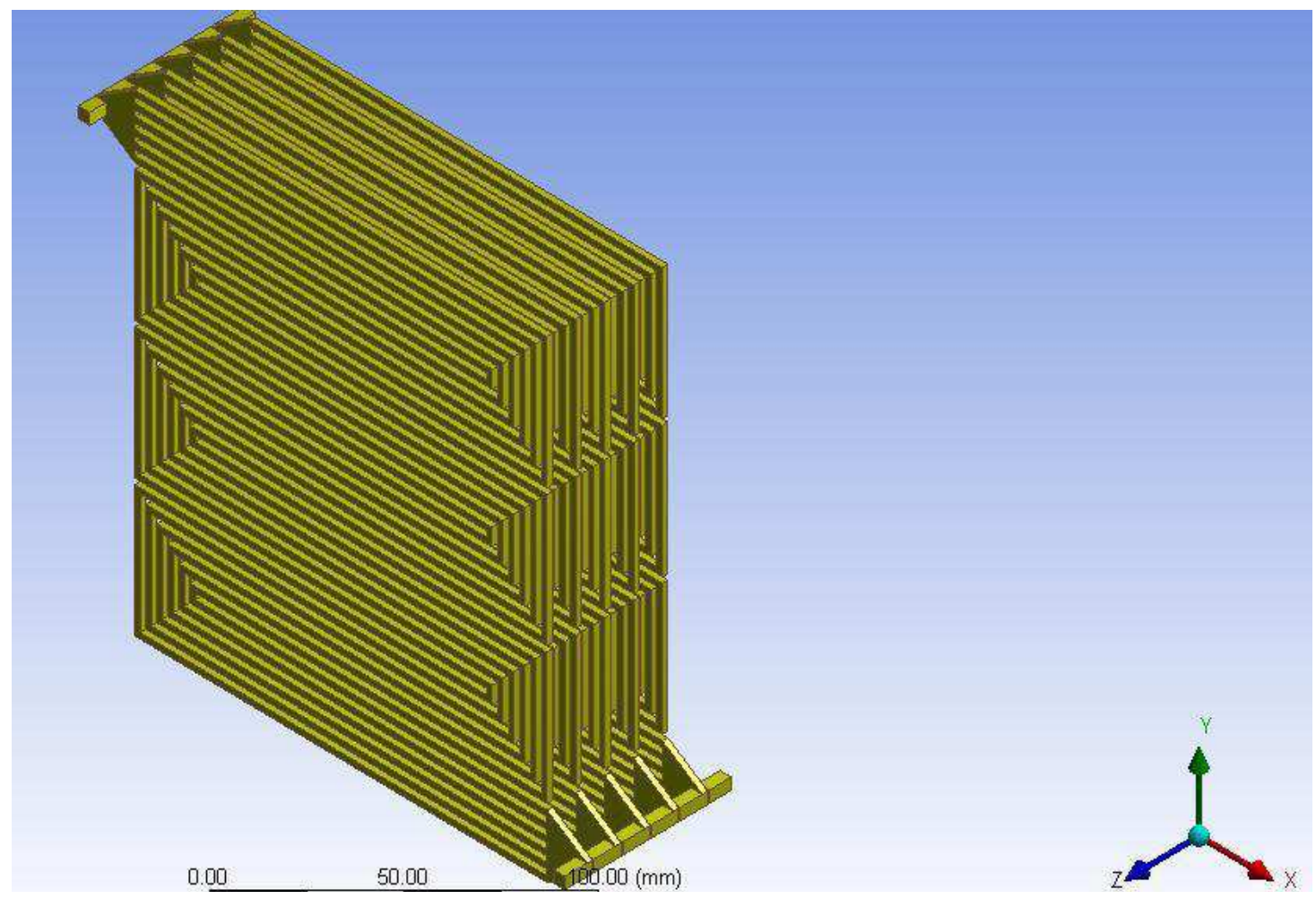

Fig. 5: $2 \times 2$ Six channel parallel serpentine flow field 


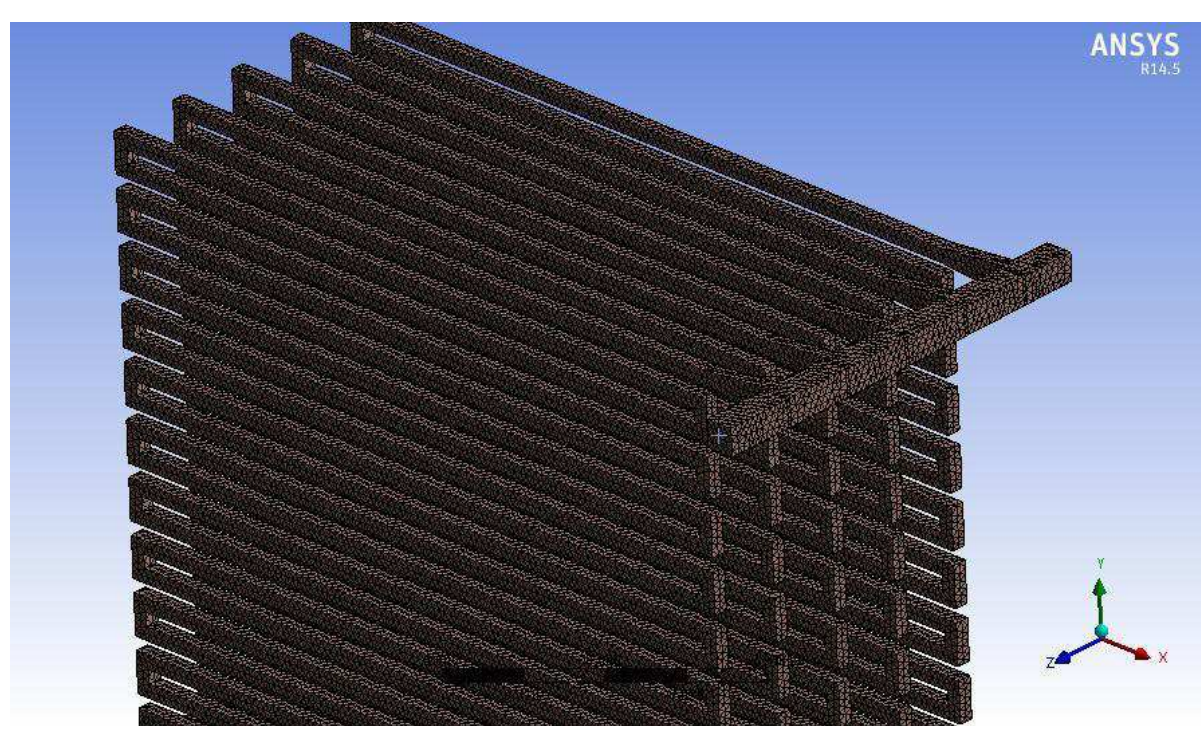

Fig. 6: Single pass parallel serpentine mesh

The solution is based on the number of nodes and elements; the quality of the mesh is the one of the criteria for the solution convergence:

Total no of nodes $\quad=132370$

Total no of elements $=411126$

\section{Boundary Conditions}

This is the interface where you specify the types of materials and boundary conditions sometimes referred to as boos. After that the rest of the volumes need to be fluid, but the solver sets them as fluid by default so they do not have to be explicitly defined as fluid. Any volume that is not explicitly defined will be set as a fluid by default. Any other surface that is not explicitly defined will automatically be set as a wall. The boundaries are:

- Hydrogen inlet

- Hydrogen outlet

- Oxygen inlet

- Oxygen outlet

The boundary conditions for the inlet gases at anode and cathode were set as "mass flow-inlet" whereas for the outlet of anode and cathode was given the boundary conditions as "pressure-outlet".

\section{Models}

Begin the simulation setup by loading the fuel cell module.

Next in the process is to set up solution controls. These controls help ensure solution convergence by employing different computational techniques. The solution guidelines from the Ansys Fuel Cell module suggest using these controls to help convergence. The exact functions of this different solution method are described in the Fluent.

\section{Solver}

A control volume approach based on commercial solver FLUENT 14.0 was used to solve the various governing equations. 3D, double precision and serial processing was used for this model. The operating pressure at inlet was given as $1,1.5$ and 2 bar and the corresponding pressure drop in each cell was identified. The outlet pressure and velocity distribution will be also simulated through the software. A comprehensive non isothermal, 3-dimensional model has been established to investigate the performance of Proton Exchange Membrane (PEM) fuel cells with straight and serpentine flow fields (Hashemi et al., 2012).

\section{Solution}

The solution initialization is to be set at specific pressure based up on fuel cell. Have found that the nearly all of convergence errors caused by divergence it can be fixed by either fixing the scaling of the mesh, or creating a higher quality mesh. It may also try lowering the value of the various under-relaxation factors if the solution does not reach a steady state. If residual graph oscillating as the solution progresses then you will need to under-relax those variables. Under-Relaxation Factors (URFs) can help the solution converge, but they can also cause the solution take longer to converge.

Therefore, the advisable to leave the URF's at their default values unless changing them is necessary.

\section{Single Pass Stack Converged Solution}

The result provide for the converged solution that shows the inlet and outlet pressure difference Fig. (7) and also the difference between inlet and outlet in Fig. (8). This procedure is repeated for all models of stack under variable input pressure as $1,1.5$ and 2 bar. 


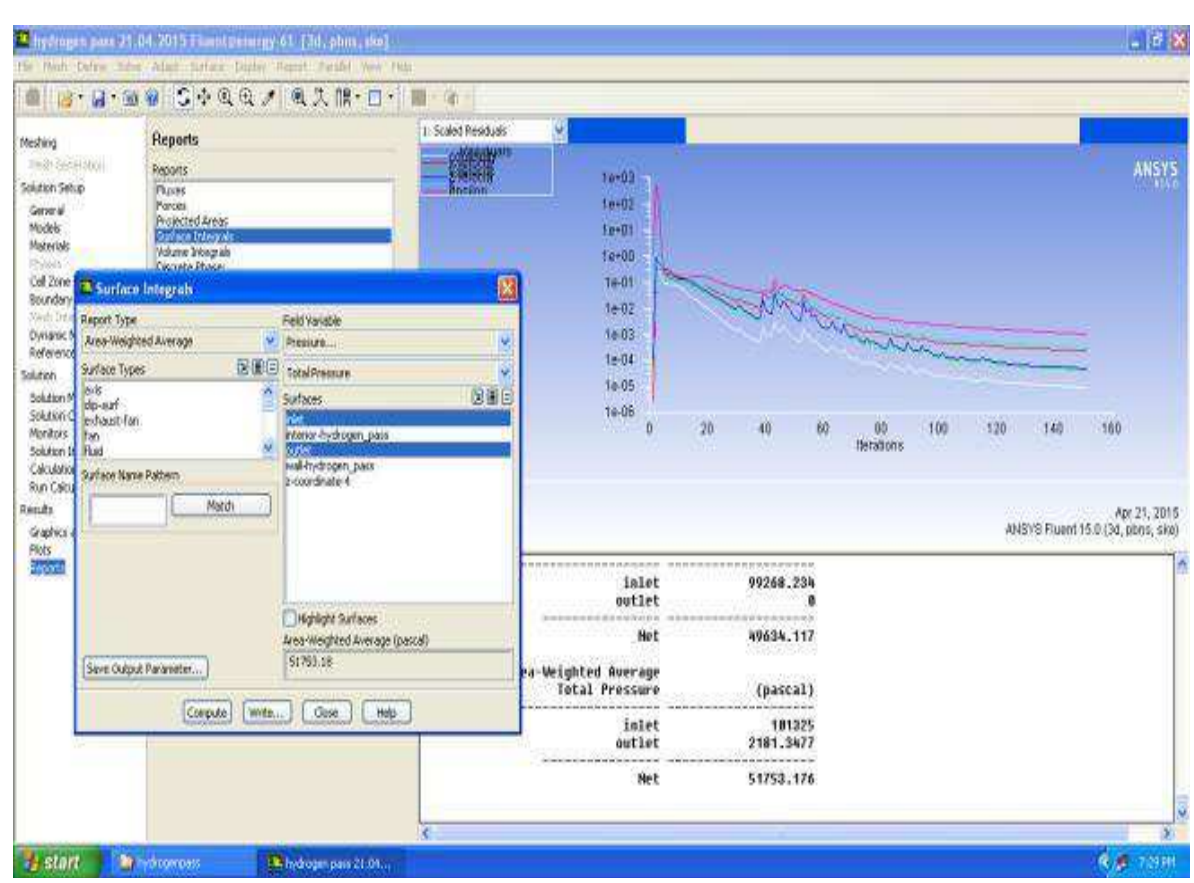

Fig. 7: Converge solution of single pass cell showing pressure difference

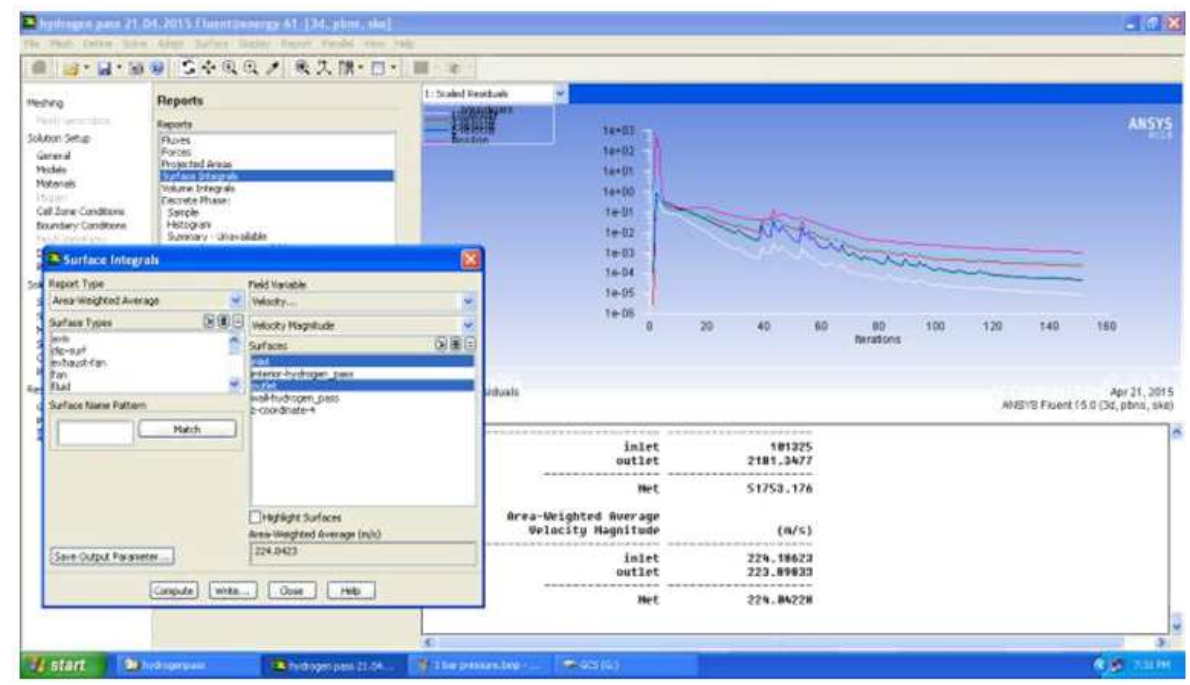

Fig. 8: Converge solution of single pass cell showing velocity difference

\section{Results and Discussion}

\section{Result of Single Pass PEMFC Stack at Ibar Input Pressure}

The performance of PEMFC with serpentine flow channel with single pass for operating pressure of 1 bar and velocity $224 \mathrm{~m} / \mathrm{s}$ has been investigated and the corresponding results were discussed here.

It is found that gradual pressure drop occurs from input to output in the flow field of single pass under 1 bar pressure. The velocity is quiet more or less constant at all flow field regions and it confirms that flow occurs at every flow regions. The pressure distribution and velocity distribution in the flow field is shown in Fig (9) and (10).

At the anode side hydrogen is send under 1 bar (101325Pa) pressure and velocity of $224 \mathrm{~m} / \mathrm{s}$ and it is found that pressure distribution at the middle of flow field is $5.5 \mathrm{e} 04 \mathrm{~Pa}$ and again the pressure drop occurs throughout the flow field region and at the outlet it is found to be $2181 \mathrm{~Pa}$. hence it shows that heavy pressure drop occurs through the flow field region. But considering the velocity it is same throughout the flow field region. The velocity at inlet and outlet are found to be 224.18 and $223.89 \mathrm{~m} / \mathrm{s}$. 


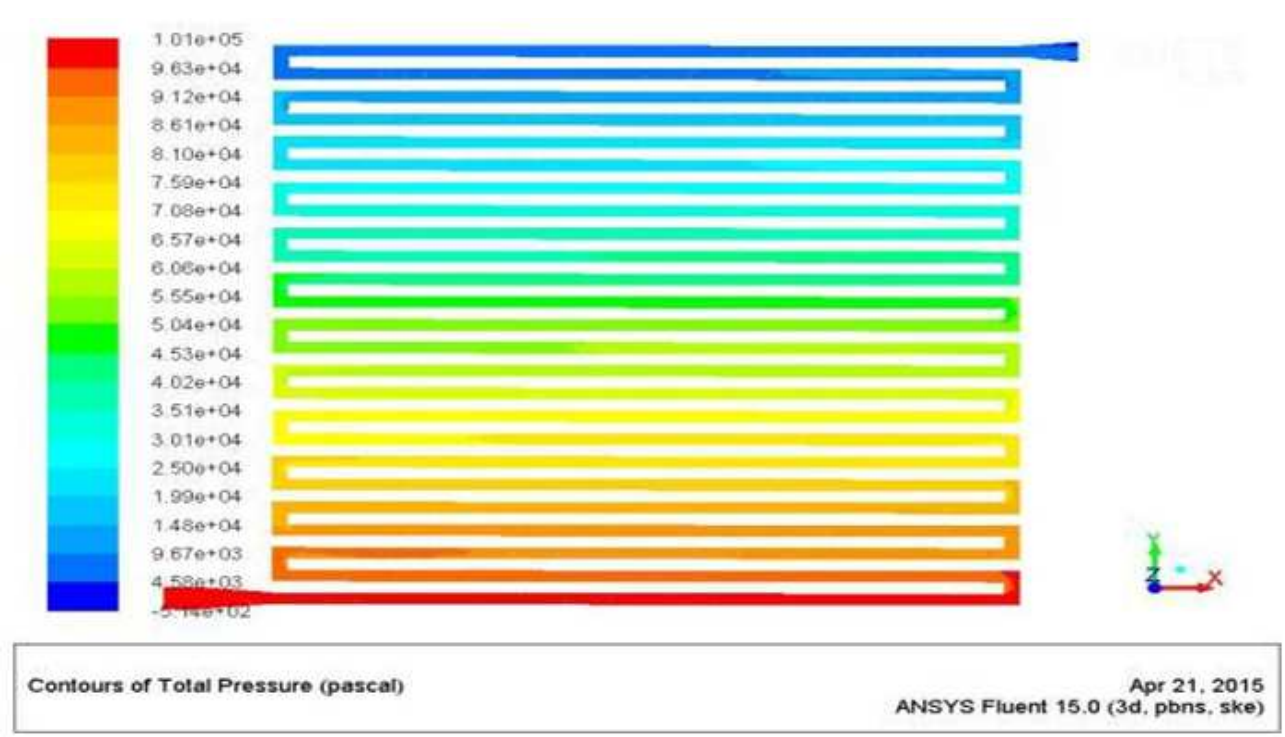

Fig. 9: Pressure distribution in the flow field

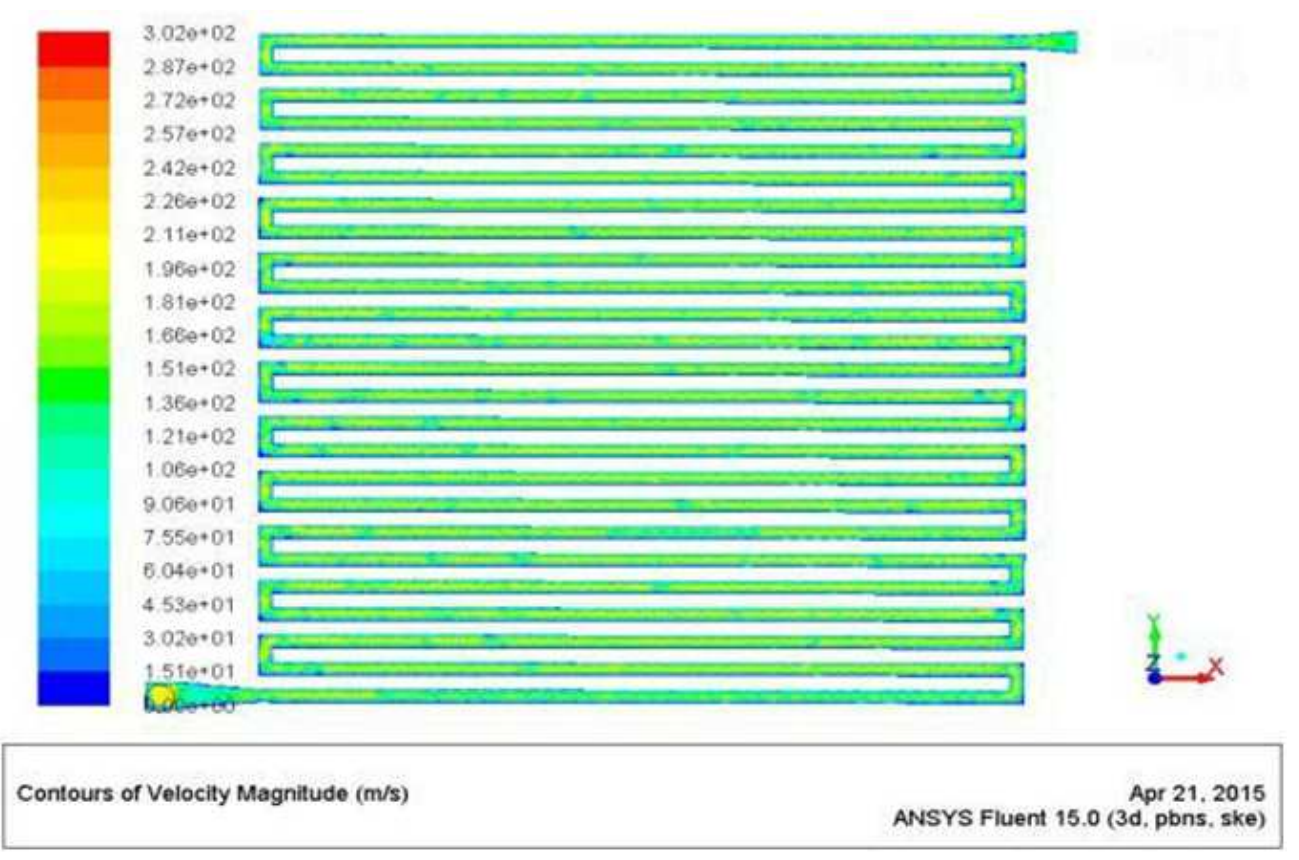

Fig. 10: Velocity distribution in the flow field

\section{Conclusion}

From the modeling study of $2 \times 2$ single pass serpentine flow field configuration for PEMFC stack, it is found that pressure drop occurs at the outlet of flow field region, while the velocity remains almost same throughout the region.

The same procedure was repeated for all the three configurations i.e., single pass, three pass and six pass under 1, 1.5 and 2 bar to find out better flow field design to supply reactants to all the cells in the stack without heavy pressure drop. The efficiency of stack will be improved by obtaining a better flow field design of bipolar plate, since manufacturing of bipolar plate costs higher.

\section{Acknowledgment}

The authors wish to thank Dr. S. Sundaram Professor and Dean, Department of mechanical Engineering at Muthayammal Engineering College (Autonomous) Rasipuram. 


\section{Author's Contributions}

A. Kalaiyarasan: Conception or design of the Data analysis and interpretation.

C. Srinivasan: Drafting the articles. Data collection and model, using control volume approach.

S. Sundaram: Critical revesion of the article and Final approval to published, English grammer correction.

\section{Ethics}

This is actual work, I responsible for any issues.

\section{References}

Birgersson, E. and M. Vynnycky, 2006. A quantitative study of the effect of flow-distributor geometry in the cathode of a PEM fuel cell. J. Power Sources, 153: $76-88$

Chen, J., 2010. Experimental study on the two phase flow behaviour in PEM fuel cell parallel channels with porous media inserts. J. Power Sources, 195: 1122-1129.

Colosquia, C.E., M.J. Cheaha, I.G. Kevrekidisa and J.B. Benzigera, 2011. Droplet and slug formation in polymer electrolyte membrane fuel cell flow channels: The role of interfacial forces. J. Power Sources, 196: 10057-10068.

Das, P.K., X. Li and Z.S. Liu, 2010. Analysis of liquid water transport in cathode catalyst layer of PEM fuel cells. J. Hydrogen Energy, 35: 2403-2416.
Frano, B., 2005. PEM Fuel Cells: Theory and Practice. 1st Edn., Academic Press, ISBN-10: 0123877105, pp: 518.

Hashemi, F., S. Rowshanzamir and M. Rezakazemi, 2012. CFD simulation of PEM fuel cell performance: Effect of straight and serpentine flow fields. J. Power Sources, 55: 1540-1557.

Jang, J.H., W.M. Yan, H.Y. Li and Y.C. Chou, 2006. Humidity of reactant fuel on the cell performance of PEM fuel cell with baffle-blocked flow field designs. J. Power Sources, 159: 468-477.

Jeon, D.H., S. Greenway, S. Shimpalee and J.W. Van Zee, 2008. The effect of serpentine flow-field designs on PEM fuel cell performance. Int. J. Hydrogen Energy.

Liu, X., W. Tao, Z. Li and Y. He, 2006. Threedimensional transport model of PEM fuel cell with straight flow channels. J. Power Sources, 158: 25-35.

Sun, L., P.H. Oosthuizen and K.B. McAuley, 2006. A numerical study of channel-to-channel flow crossover through the gas diffusion layer in a PEM-fuelcell flow system using a serpentine channel with a trapezoidal cross-sectional shape. J. Power Sources 45: 1021-1026.

Shimpalee, S. and J.W. Vanzee, 2006. Numerical studies on rib and channel dimension of flow field on PEMFC performance. 